\title{
Cari Açık Sorununun Temel Nedenleri ve Sürdürülebilirliği: Türkiye Örneği
}

\author{
Utku ALTUNÖZ*
}

Öz

Çalışmanın amacı Türkiye'de cari açığın sürdürülebilir olup olmadığı test edilesidir. Söz konusu analiz için 1994:04-2013:04 dönemleri incelenmiş olup, seriler arasında tüm dönemlerde eş-bütünleşme ilişkisinin olduğu ve her ne kadar kısa dönemde sapmalar olsa da uzun dönemde söz konusu sapmaların ortadan kalktığl sonucuna ulaşılmıştır. Ekonometrik modelimize göre Türkiye'nin cari açık problemi zayıf bir șekilde sürdürülebilmektedir.

Anahtar Kelimeler: Cari Açık, Finansman Kalitesi, Sürdürülebilirlik

JEL Sınıflandırması: E60, E63,F10

\section{Fundamental Reasons of Current Deficit and Sustainabilty:} The Case of Turkey

\begin{abstract}
The aim of this study is to test if current deficit of Turkey is sustainable or not. Turkey was tested by Johansen's co integration method by using the data of 1994:042013:04 period. According to the result of empirical analysis, co-integration relation exist and it was understood that the current account deficit has been determined as weakly sustainable.
\end{abstract}

Keywords: Current Account Deficit, Financing Quality, Sustainability

JEL Classification: E60, E63,F10

\section{Giriș}

90’lı yıllarda baş göstermeye başlayan cari açılk problemi, özellikle finansal krizlerin nedenleri arasında baş sıralarda yer almaktadır. Erken

* Yrd.Doç.Dr., Sinop Üniversitesi İIBFF Dekan Yrd., İşletme Bölüm Bşk. E-posta: utkual@hotmail.com 
Sayfa/Page | 116

İGÜSBD Cilt: 1 Sayı: 2 October 2014

uyarı sistemi olarak ta kabul gören bu konu, Türkiye ekonomisi için de önem arz etmektedir. Özellikle literatürde cari açığın GSYİH'ya oranının \%5 olması gerektiği ve bu değerin eşik değer olduğu öne sürülmektedir. Türkiye, Latin Amerika ülkeleri gibi ülkelerin yaşadıkları finansal krizlerde de Cari Açık/GSYİH oranı önemli bir erken uyarı sinyali olarak karşımıza çıkmaktadır.

Türkiye ekonomisinin dış borç ve sermaye akışının da etkisi ile yüksek büyüme performansı yaşadığı yadsınamaz bir gerçektir. Bununla birlikte dış ticaret haddinde ve cari açığında da paralel bir artışı beraberinde getirmiştir. Türkiye'nin 2011 yılında cari açığı GSYİH'nın \%10 una ulaşmıştır.

Çalışmamızın amacı cari açığın temel sebeplerini ve problemin çözümü için finanman kalitesini belirlemek ve ne derece sürdürülebileceğini ortaya koymaktır. Çalıșmamızda kuracağımız ekonometrik modelle çalışmamız güçlendirilerek ve sonuçların literatüre uygunluğu analiz edilecektir.

\section{Cari Açığın Tanımı}

Ülkelerin belirli dönemde kazandıkları döviz gelirleri ve harcadıkları döviz giderleri ödemeler bilançosunda kayıtlanmaktadır. Cari işlemler ve finans hesabı olarak ikiye ayrılan ödemeler bilançosu, cari açığın durumunun izlenmesinde önem taşımaktadır. Finans hesabını doğrudan yabancı sermaye yatırımları, portföy yatırımları vb döviz girişleri oluşturmaktadır. Söz konusu yatırımlar, kâr transferleri, cari işlemler hesabının diğer gelirler bölümünde yer almaktadırlar. Finans hesabının görevi, cari işlemler açığının finansmanını sağlamaktır. Eğer finans hesabıyla sağlanamadığında net hata ve noksan hesabıyla, onunda yetmediği durumlarda resmi rezervlerle kapatılmaktadır.

Cari işlemler açığı kavramı özellikle 1980'li yıllarda sermaye hareketlerinin serbestleşmesi konusundaki engellerin ortadan kalkmasıyla adından daha fazla söz ettirir bir kavram haline gelmiştir. Yüksek sermaye girişlerinin etkisiyle küresel cari hesap açığının artarak sürmesi başta Amerika Birleşik Devletleri olmak üzere diğer birçok ülkede ekonomik istikrara ilişkin önemli kaygılara yol açmıştır. Yüksek sermaye girişlerine paralel olarak ülkeleri yüksek cari açıkları finanse edebilmelerine rağmen açıkların kalitesi ve sürdürebilirliği ayrı bir tartışma konusu haline gelmiştir. 1990lu ylllar, Türkiye ve benzeri gelişmekte olan ülkeler için cari açıkların sürdürülebilir olup olmadığının tartışılır olduğu yıllar haline gelmiştir. 1989-2004 yılları arasında yurt dışı yerleşiklerinin toplam 
sermaye girişlerinin \%25 i portföy yatırımlarından oluşmaktaydı. \%18 lik kısmını ise kısa vadeli kredi girişleri oluşturmaktaydı. Bu miktar, toplam sermaye girişlerinin neredeyse yarısını oluşturduğu için giren sermayenin geri dönmesi yada girişin sürdürülebilir olup olmadığı tartışılır hale gelmiştir. Türkiye'de 1994 ve 2001 krizlerinin sebepleri arasında cari açı önemli rol bir paya sahiptir. Cari Açık / GSYİH oranlarına bakıldığında 1993 yılında yaklaşık \%3,5 oranında açık verilirken, 2000 yılında yaklaşık \%5 açık verilmiş ve kriz ortamı oluşmuştur.

Grafik 1: Türkiye’de 1994-2012 Dönemleri Arası Cari Açık (\%)

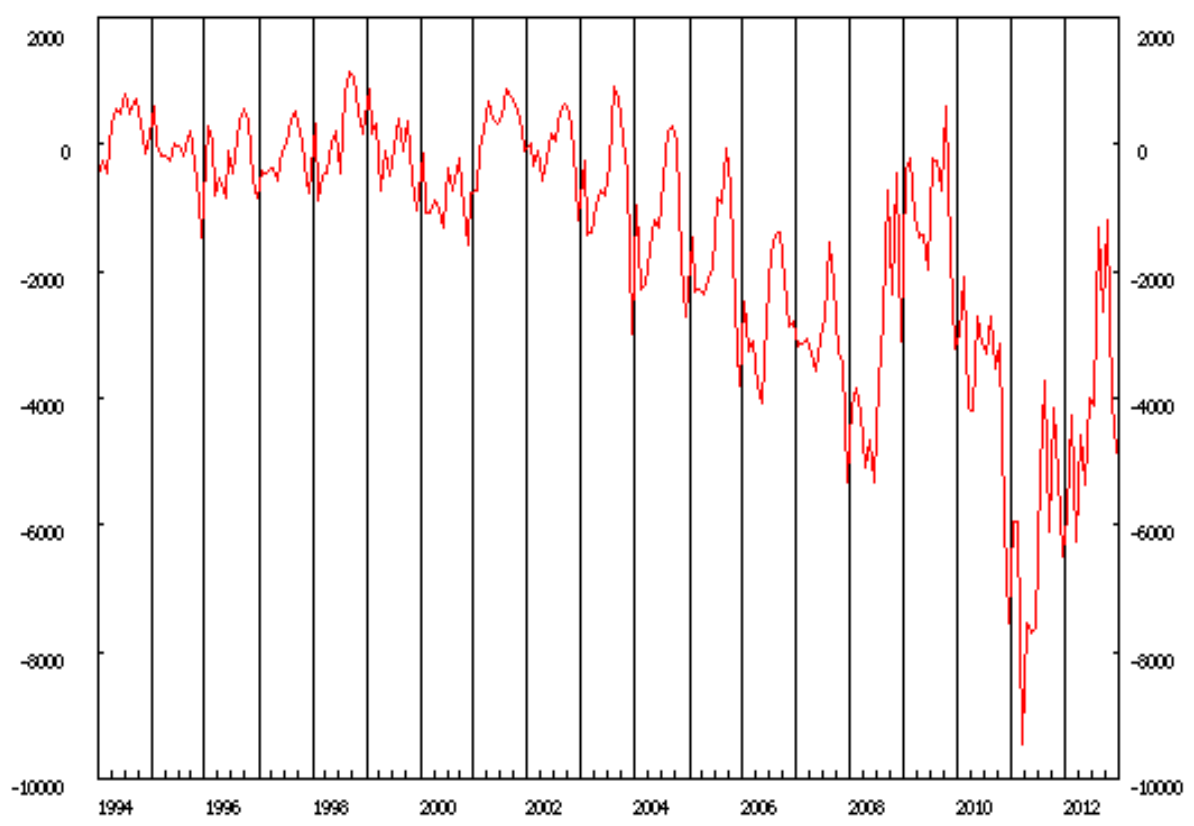

Kaynak: TCMB

Grafik 1'de izlendiği üzere Türkiye ilgili yıllarda cari açı sorunu ile karşı karşıyadır. 2008 Küresel Ekonomik Krizine kadar oldukça istikrarlı bir seviyede seyreden Türkiye'nin cari açığı, küresel krizinin de etkisiyle 2009-2010 yılları arasında önemli ölçüde azalmıştır. Krizin etkisinin azalması ile birlikte günümüzde eski seviyelere çıktığı açıç̧a izlenebilmektedir.

2002 yılından itibaren yaşanan olumlu gelişmelere rağmen, aynı yıldan itibaren Türkiye'de cari açık temel makroekonomik sorun olarak 2012 yılına kadar önemini artırarak devam etmiştir. Aşırı değerli yerli paradan kaynaklanan döviz kurlarında yaşanacak bir artış ile sorunun

Sayfa/Page | 117 İGÜSBD Cilt: 1 Sayı: 2 Ekim /

October 2014 
çözümüne kısa vadede katkıda bulunulmasına ilişkin gelişmeler 2011 yılı ikinci yarısında yaşanmıştır. Döviz kuru artışı 2011 yılı sonu ve 2012 başında kendisini göstermeye başlamıştır. Nisan-2012'de ise orta ve uzun vadede çözüme kalıcı katkıda bulunulması amacıyla hükümet tarafından yeni bir teşvik programı açıklanmıştır.

Sayfa/Page | 118

\section{Cari Açığın Teorik Altyapısı}

Cari açı̆̆ı birbiriyle bağlantılı üç farklı yaklaşımla açlklayabilmekteyiz.

$$
\begin{aligned}
& C D_{t}=N X_{t}+r_{t} B_{t}+T R_{t} \\
& C D_{t}=B_{t+1}-B_{t} \\
& C D_{t}=r_{t} B_{t}+T R_{t}+Y-C_{t}-T_{t}-G_{t}=S_{t}-I_{t}
\end{aligned}
$$

İlk denklemde cari açığın tanımı mal ticareti, dış borca ilişkin faiz ödemeleri ve transfer ödemeleri ile yapılmaktadır.

$\boldsymbol{N} \boldsymbol{X}_{\boldsymbol{t}}$ : Mal ve hizmet ihracatı (Net)

$\boldsymbol{B}_{\boldsymbol{t}}$ :Dış borcu olan ülkeler için dış borç stokudur. Ayrıca bono,tahvil,krediler, fiziki sermaye ve hisse senedi gibi net dış varlıkları ifade eder.

\section{$\boldsymbol{r}_{t}$ : Uluslararası faiz oranı}

$\boldsymbol{r}_{\boldsymbol{t}} \boldsymbol{B}_{\boldsymbol{t}}$ : Dış borcu olan ülkelerde dış borç faiz ödemesidir. Ayrıca dış varlıklardan sağlanan net getiriyi ifade eder.

$\boldsymbol{T R}_{\boldsymbol{t}}$ : kamu ve özel kesim net transfer harcamaları

Denklemdeki mal ve hizmet ihracatı kalemini olumsuz etkileyen kalem $r_{t} B_{t}$ kalemidir. Özellikle ülkenin borçlu olması, bu kalemin negatif değerli olmasına neden olmaktadır. Bu durum da mal ve hizmetler kalemini olumsuz yönde etkilemektedir. Matematiksel olarak transfer harcamaları pozitiftir ve cari dengeyi olumlu yönde etkilemektedir. Mal ticaretindeki açıklar ve dış borç faiz ödemeleri cari açığın nedeni olarak gösterilebilir.

Denklem (2) de diş varlıklar ile açılklanmaktadır. $B_{t+1}-B_{t}$; net diş varlık değișimini göstermektedir. Bu bilgiler doğrultusunda söz konusu değerin negatif değer alması, ülkenin cari açık vermesi anlamına gelmektedir. 
Denklem (3) de ise yatırım ve tasarruf dengesi kanalıyla cari açı açıklanmaktadır. Denklemin $\left(C_{t+} I_{t}+G_{t}\right)$ kısmı ülkedeki toplam giderleri, $\left(r_{t} B_{t}+T R_{t}+Y_{t}\right)$ ise ülkedeki gelirler toplamını ifade etmektedir. Giderler kısmı sırasıyla özel tüketim harcamaları, özel ve kamu yatırım harcamaları ve cari kamu harcamalarını ifade etmektedir. $Y_{t}$ Yurtiçi üretimi ifade ederken $S_{t}$ özel ve kamu tasarruf toplamını ifade etmektedir.

O halde;

$C D_{t}=S_{t}-I_{t}$ şeklinde ifade edilebilmektedir. Eğer bu eşitlik negatif değer alırsa ülkede iç tasarruf eksiği olduğu anlaşılmaktadır. Burada temel neden kamuve/veya özel kesimde harcama kalemlerinin fazla olmasıdır.

\section{2000'li Yıllar ve Türkiye'nin Cari Açık Sorunu}

2001 krizi sonrasında gerçekleştirilen istikrar programları sonucunda enflasyon kontrol altında tutulmuştur. Merkez bankasının bağımsızlığının sağlanması ve bankacılık sektöründeki reformlar, düzelen bütçe göstergeleri ile birlikte ekonominin seyrini olumlu yönde etkilemiştir. Yaşanan olumlu gelişmelere karşın, bu dönemde cari işlemler dengesinde süreç tersine işlemiştir. Ekonomik daralmanın yaşandığı 2001 yılında GSYH'nın \%2'si kadar fazla veren cari işlemler dengesi, 2002 yllından itibaren açık verecek şekilde Türkiye'nin en önemli ekonomik sorunlarından birisi olarak varlığını her geçen yıl daha da hissettirmiştir.

Tablo 1: Cari İşlemler Dengesi ve Cari Açık/GMYH Oranı (2002-2011)

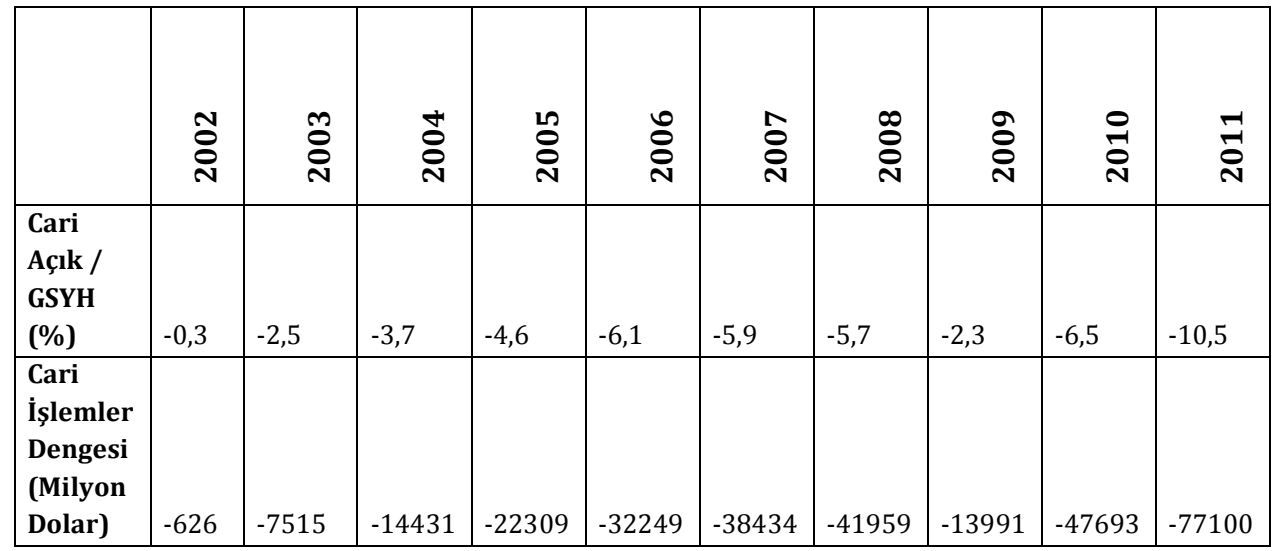

Kaynak: TCMB

Tablo 1 den izlendiği gibi 2002 yılından 2011 yılına kadar Cari Açı / GSYİH oranı artış eğilimine girmiş olup 2011 yılında eşik değerin iki katına 
ulaşmıştır. Cari işlemler dengesindeki artış ta dikkat çekicidir. TCXMB verilerine göre 2012 yılı cari işlemler açı̆̆ı, bir önceki yıla göre 28.3 milyar dolar azalarak 48.8 milyar dolara gerilemiş oldu. 2013 yılında ise cari işlemler açığı 65 milyar 4 milyon dolar

Sayfa/Page | 120 İGÜSBD Cilt: 1 Sayı: 2 Ekim / October 2014

1990 yılından itibaren yaşanan ekonomik krizlerin ödemeler bilançosu kaynaklı oluşu ve kriz yıllarından önce Cari Açık/GSYH oranının \%5'e kadar yükselmesi nedeniyle cari açık / GSYH'ya oranının \%5 ve daha büyük bir orana ulaşması ekonomi açısından bir risk olarak kabul edilmektedir1.

Türkiye ekonomisi 2002'den itibaren ylllk ortalama \%5,5 büyüyerek, 300 milyar dolar GSYIH'dan 800 milyar dolar GSYİH düzeyine yaklaşmıștır. Gelecek 10 yılda aynı hızla büyüyen bir Türkiye'nin 2023'te yıllık milli geliri 2 trilyon dolara varması kaçınılmazdır. Bununla birlikte cari açı Türkiye ekonomisi için bütün zaafları bünyesinde barındıran en kritik, en şeffaf ve nihai göstergedir. Bu nedenle, işsizlik ve enflasyon sorunlarını da eş zamanlı çözmeye imkân verecek GSYH'nın \%3'ü ya da altında bir cari açığı sağlayacak yapısal politikalarda yoğunlaşma kaçınılmazdır.

\section{Türkiye'de Cari Açığın Temel Nedenleri}

Ülkemizde cari açığın temel nedenlerini baktığımızda ilk karşımıza çıkan etmen iç tasarrufların yatırımlara yetmemesidir. Son yıllarda Türkiye'de iç talep aşırı derecede canlanmış, iç tasarruf oranları 1992'deki \%23 seviyelerinden, 2011'de \%12.8'lere kadar düşmüştür. Buna karşı-llk, 2011 yılında Türkiye'de yatırımların GSYIH'ya oranı, \%23.1'dir². İç tasarruf arttırıcı politikalardan uzak olan ülkemiz, faizlerin yüksek kalması, bütçenin daha da sıkılaştırılması ve iç talebin azaltılması gibi politikalarla tasarruf oranlarını arttırabilecektir.

Diğer bir neden ise Dış Ticaret Açığıdır. Cari işlemler açığının en önemli nedeni, dış ticaret açığıdır. Türkiye'de 1980 öncesinde, ithal ikameci üretim politikası izlenmiş ve ihtiyaç duyulan bütün malların yurt içinde üretilmesine çalışılmıştır. 24 Ocak 1980 kararlarıyla birlikte, ülkenin dış dünya ile serbest ticaret yapmasının önü açılmış ve ihracata dayalı ekonomik büyüme modeli uygulamaya konulmuştur. Ancak, gerekli yapısal

${ }^{1}$ O. Murat Telatar, Harun Terzi, “Türkiye'de Ekonomik Büyüme ve Cari İşlemler Dengesi İlişkisi", Atatürk Üniversitesi İktisadi ve İdari Bilimler Dergisi, 23:2,2009, 119.

${ }_{2}^{2}$ IMF, Wold Economic Outlook, April 2011. 
düzenlemeler yapılmadan başlayan bu dışa açılma süreci, ihraç edilenden daha fazlasının ithal edilmesiyle ve dış ticaret açığıyla sonuçlanmıştır.

Liberalleşme sürecinde özellikle ithal ikamecilikten vazgeçilerek ihracata dayalı büyüme stratejileri izlenmiştir. İzlenen politikaların sonucunda gerekli alt yapının oluşturulmaması sonucu yüksek enflasyon ile karşı karşıya kalınmıştır. Özellikle bu dönemde satınalma gücünün yetersiz olduğu bir iç pazar mevcuttu. Bu nedenle üretim optimal ölçekle yapılamamıştır. Küçük sanayiciler ileri teknolojiye yönelik tesisler kuramamıșlardır.

Tablo 2: Türkiye'nin 2006-2012 Dönemi Dış Ticaret Dengesi (Milyar \$)

\begin{tabular}{|c|c|c|c|c|}
\hline & İhracat & İthalat & Denge & İhracat/Ithalat (\%) \\
\hline $\mathbf{2 0 0 6}$ & 86 & 139 & -53 & 0,618705036 \\
\hline $\mathbf{2 0 0 7}$ & 107 & 170 & -63 & 0,629411765 \\
\hline $\mathbf{2 0 0 8}$ & 132 & 201 & -69 & 0,656716418 \\
\hline $\mathbf{2 0 0 9}$ & 102 & 140 & -38 & 0,728571429 \\
\hline $\mathbf{2 0 1 0}$ & 113 & 185 & -72 & 0,610810811 \\
\hline $\mathbf{2 0 1 1}$ & 134 & 240 & -106 & 0,558333333 \\
\hline $\mathbf{2 0 1 2}$ & 100 & 156 & -56 & 0,641025641 \\
\hline
\end{tabular}

Kaynak: TCMB-EVDS-Dış Ticaret Geniş Ekonomik Kategorileri Sınıflamasına Göre.

*2012 değerleri ilk 8 aylık döneme aittir.

Tablo 2'de Türkiye'de cari açığın devamlı olarak arttığı ve 2001 yılında en yüksek değerine ulaştığı görülmektedir. İhracatın ithalatı karşılama oranları, \%60 civarındadır.

Enerjide dışa bağımlılık ve artan enerji fiyatları diğer bir cari açık nedenidir. Son yıllarda enerji fiyatlarının artmasının da etkisiyle, enerji ithalatı, cari açık içinde önemli bir yer tutmaktadır.

Sayfa/Page | 121 İGÜSBD Cilt: 1 Sayı: 2 Ekim /

October 2014 
Tablo 3: Enerji İthalatının Ekonomideki Yeri

\begin{tabular}{|c|c|c|c|c|c|c|c|c|}
\hline \multirow{8}{*}{$\begin{array}{r}\text { Sayfa/Page | } \mathbf{1 2 2} \\
\text { İGÜSBD } \\
\text { Cilt: } 1 \text { Sayı: } 2 \\
\text { Ekim / } \\
\text { October } 2014\end{array}$} & & $\begin{array}{l}\text { Enerji } \\
\text { İtalatı } \\
\text { (Milyar } \\
\text { USD) }\end{array}$ & $\begin{array}{l}\text { Toplam } \\
\text { İthalat } \\
\text { (Milyar } \\
\text { USD) }\end{array}$ & $\begin{array}{l}\text { Enerji } \\
\text { İthalatının } \\
\text { Toplam } \\
\text { İthalat } \\
\text { İçindeki Payı } \\
(\%)\end{array}$ & $\begin{array}{l}\text { Cari Açık } \\
\text { (Milyar } \\
\text { USD) }\end{array}$ & $\begin{array}{l}\text { Enerji } \\
\text { İthalatının Cari } \\
\text { Açı İçindeki } \\
\text { Payı (USD) }\end{array}$ & $\begin{array}{l}\text { Enerji } \\
\text { Giderleri } \\
\text { Hariç Cari } \\
\text { Açlk (Milyar } \\
\text { USD) }\end{array}$ & $\begin{array}{l}\text { Ham } \\
\text { Petrol } \\
\text { Varil } \\
\text { Fiyatlari } \\
\text { (USD) }\end{array}$ \\
\hline & 2006 & 29 & 139 & 21 & 32 & 90 & 3.4 & 58 \\
\hline & 2007 & 33 & 170 & 20 & 38 & 88 & 4.6 & 64 \\
\hline & 2008 & 48 & 202 & 23 & 41 & 116 & -6.8 & 91 \\
\hline & 2009 & 29 & 140 & 21 & 13 & 223 & -16.5 & 53 \\
\hline & 2010 & 38 & 185 & 20 & 46 & 82 & 8.1 & 91 \\
\hline & 2011 & 54 & 240 & 22 & 77 & 70 & 23 & 87 \\
\hline & 2012* & 40 & 156 & 24 & 34 & 113 & -4.7 & 108 \\
\hline
\end{tabular}

Kaynak: TCMB ve TUiK, 2012 yllı verileri, ilk 8 ayllk dönemi kapsamaktadır.

Tablo 3 'te 2011 yılında 54 Milyar Dolarlık enerji ithal edildiği, bunun toplam ithalatın \%22.5'ine, cari açığın \%70'ine karşılık geldiği görülmektedir.

Türkiye'de uygulanmakta olan genişletici para ve maliye politikaları, cari açı̆̆ın bir diğer nedenidir. Yüksek büyüme rakamlarına ulaşabilmek için uygulanan bu politikalar, iç talebi arttırırken cari açık üzerinde olumsuz bir etki yaratmaktadır. Cari açıkla mücadele için yalnızca para politikasının değil, maliye politikasının da sıkılaştırılması gerekmektedir. Çünkü genişletici maliye politikasına paralel olarak meydana gelen kamusal bütçe açıkları, iç faiz oranlarının yükselmesine neden olmaktadır. Bu durumun sonucu ülkeye daha fazla sermaye girer, o da ülkede döviz kuru düşüşüne yol açar³.

Doğrudan yabancı yatırımları ve portföy yatırımlarının kâr transferleri, Türkiye'de cari açığın artışında önemli bir yere sahiptir. Yabancı yatırım ve portföy yatırımlarının kâr transferleridir. Türkiye'de

${ }^{3}$ C.F. Marinheiro, "Ricardian Equivalence, Twin Deficits, and the Feldstein-Horioka Puzzle in Egypt", Grupo de Estudos Monetarios e Financeiros, Faculty of Economics University of Coimbra, Portugal. http://evds.tcmb.gov.tr (Erişim: 27.08.2013). 
yabancıya satılan kamu altyapı yatırımları ile kârlı özel işletmelerin döviz olarak dışarıya kâr transfer etmesi cari açığı olumsuz yönde etkilemektedir.

Tablo 4: Doğrudan Yabancı Yatımlar ve Portföy Yatırımlarının Kâr Transferleri (Milyar \$)

\begin{tabular}{|l|l|l|l|l|l|}
\hline & DYYKT & PYKT & CA & DYYKT/CA (\%) & PYKT/CA (\%) \\
\hline $\mathbf{2 0 0 6}$ & 1182 & 3463 & 32249 & 3.7 & 10.7 \\
\hline $\mathbf{2 0 0 7}$ & 2213 & 3735 & 38434 & 5.8 & 9.7 \\
\hline $\mathbf{2 0 0 8}$ & 2940 & 3523 & 41524 & 7.1 & 9 \\
\hline $\mathbf{2 0 0 9}$ & 2914 & 2994 & 13370 & 21 & 22 \\
\hline $\mathbf{2 0 1 0}$ & 2865 & 3149 & 46643 & 6 & 6.8 \\
\hline $\mathbf{2 0 1 1}$ & 3 & 3382 & 77199 & 4 & 4.4 \\
\hline $\mathbf{2 0 1 2} *$ & 1396 & 2370 & 34462 & 4 & 6.8 \\
\hline
\end{tabular}

Sayfa/Page | 123

İGÜSBD

Cilt: 1 Sayı: 2

Ekim /

October 2014

Kaynak: TCMB-EVDS-Ayrıntılı Sunum. *2012 değerleri ilk 7 aylık döneme aittir.

DYYKT: Doğrudan Yabancı Yatırım Kâr Transferleri

CA: Cari açlk

PYKT: Portföy Yatırımları Kâr Transferleri

Kâr transferleri cari acık içinde önemli bir yer tutmaya başlamıştır. Tablo 4 te, doğrudan yabancı yatımlar ve portföy yatırımlarındaki kâr transferlerinin cari açı̆̆ı ne ölçüde yükselttiği izlenebilmektedir.

Türkiye'nin borçlanmasında dış borcun yüksek oluşu da cari açığı artıran bir etmendir. 
Tablo 5: Dış Borç Stokunun Cari Açığa Etkisi (Milyar \$)

Sayfa/Page | 124

İGÜSBD

Cilt: 1 Sayı: 2 Ekim / October 2014

\begin{tabular}{|l|l|l|l|l|l|l|l|}
\hline & $\begin{array}{l}\text { Özel } \\
\text { Kesim }\end{array}$ & $\begin{array}{l}\text { TCMB } \\
\text { Dış } \\
\text { Borç } \\
\text { Stoğu }\end{array}$ & $\begin{array}{l}\text { Kamu } \\
\text { Dış } \\
\text { Borç } \\
\text { Stoğu }\end{array}$ & Toplam & $\begin{array}{l}\text { Diş Borç } \\
\text { Faiz } \\
\text { Ödemeleri }\end{array}$ & $\begin{array}{l}\text { Cari } \\
\text { Açık }\end{array}$ & $\begin{array}{l}\text { Diş Borç Faiz } \\
\text { Ödemeleri } \\
\text { Cari Açı }\end{array}$ \\
\hline $\mathbf{2 0 0 6}$ & 120 & 15 & 71 & 206 & 6 & -32 & $-0,1875$ \\
\hline $\mathbf{2 0 0 7}$ & 160 & 15 & 73 & 248 & 7 & -38 & $-0,184210526$ \\
\hline $\mathbf{2 0 0 8}$ & 188 & 14 & 78 & 280 & 8 & -42 & $-0,19047619$ \\
\hline $\mathbf{2 0 0 9}$ & 172 & 13 & 83 & 268 & 7 & -13 & $-0,538461538$ \\
\hline $\mathbf{2 0 1 0}$ & 189 & 11 & 88 & 288 & 5 & -48 & $-0,104166667$ \\
\hline $\mathbf{2 0 1 1}$ & 203 & 10 & 95 & 308 & 5 & -77 & $-0,064935065$ \\
\hline $\mathbf{2 0 1 2} *$ & 207 & 9 & 100 & 316 & 3 & -34 & $-0,088235294$ \\
\hline
\end{tabular}

Kaynak: TCMB Ödemeler Bilançosu Ayrıntılı Sunum ve Dış Borç İstatistikleri.

*2012 değerleri, ilk 7 aylık döneme aittir.

Tablo 5 ten izlenildiği gibi Türkiye dışa bağımlı borç stratejisi izlemektedir. Bunun doğal sonucu olarak toplam diş borç stoğu devamlı artış kaydetmektedir. Bu borçların faiz ödemeleri cari açı̆̆ın artmasına neden olmaktadır.

2013 yılına gelindiğinde, dış ticaret açığını yıl boyunca devam eden artış ve aralıkta hizmetler ve gelir kalemindeki zayıflığın etkisiyle cari açık 2013'ün tamamında 65 milyar dolar ile önemli bir seviyededir. 2013 yılı cari işlemler açığı, bir önceki yıla göre 16 milyar 507 milyon dolar artarak 65 milyar 4 milyon dolara yükselirken, parasal olmayan altın hariç cari işlemler açığı 983 milyon dolar azalarak 53 milyar 223 milyon dolara gerilemiştir.

\section{Cari Açığın Sürdürülebilirliği Konusunda Literatür}

Yücel ve Yanar (2005), Cari açığın sürdürülebilir olup olmadığı konusunda 1994-2003 yılları arasında ihracat ve ithalat arasındaki uzun süreli ilişkiyi irdelemiş̧lerdir. Engle-Granger iki aşamalı eş-bütünleşme testlerini kullandıkları çalışmalarında ithalat ve ihracat arasında uzun dönemli ilişki olmadığı sonucuna ulaşmıştır. Bu durumun istatistiki 
açılklaması Türkiye'nin cari işlemler açıklarının sürdürülemez olduğu şeklindedir.

Matsubayashi (2005), 1975:1-1998:2 dönemleri için ABD'deki cari açığın sürdürülebilir olup olmadığını analiz etmiştir. Çalışmada her koentegrasyon denklemini dört farklı gecikme uzunluğu kullanarak tahmin etmiş ve ABD cari açı̆̆ının büyük olasılıkla sürdürülebilir olduğu sonucuna ulaşmiştır.

Peker (2009), Türkiye'de cari işlemler açığının sürdürülebilirliğini, 1992-2007 dö-nemi aylık verilerini kullanarak, Johansen eş-bütünleşme yöntemi yardımıyla analiz etmiştir. Çalışma sonucunda, ihracat ve ithalat serileri arasında uzun dönemli ilişki bulunmasına rağmen, eş-bütünleşme katsayısının birden küçük çıkması nedeniyle, Türkiye'de cari işlemler açığının ancak düşük formda sürdürülebilir olduğu, döviz gelirlerinin döviz giderlerinden daha az olduğu sonucuna ulaşmıştır.

Fountas ve Wu (1999) ABD için cari açığın sürdürülebilir olup olmadığı konusunda yaptıkları çalışmada eş-bütünleşme yöntemini kullanmışlardır. 1967-1994 veri seti ile yaptıkları çalışmanın sonucunda ABD'de cari açığın sürdürülemez olduğu sonucuna ulaşmışlardır.

Göçer ve Mercan (2011), Türkiye için cari açı̆̆ın sürdürülebilirliği ile ilgili yaptıkları açlışmada 1992:01-2010:3 için sınır testi yaklaşımını kullanmışlardır. Söz konusu çalışmada zayıf formda cari açığın sürdürülebilir olduğu sonucuna ulaşmışlardır.

\section{Ampirik Analiz}

1994:04-2013:04 dönemlerini kapsayan ampirik analizimizde gelirler değişkeni ve giderler değişkeni kullanılmıştır. Gelirler değişkeni I ile giderler değişkeni ise C ile ifade edilmektedir. Veri seti TCMB Elektronik Veri Dağıtım sisteminden temin edilmiştir.

- Gelirler Değişkeni:

- Mal ve hizmet ihracatı

- Hizmet gelirleri

- Transfer ödemeleri

- Dış borç faiz gelirleri

- Giderler Değişkeni:

- Mal ve hizmet ithalatı

- Hizmet Giderleri

- Dış borç faiz ödemeleri

Sayfa/Page | 125

İGÜSBD

Cilt: 1 Sayı: 2

Ekim /

October 2014 
Türkiye'de cari açığın sürdürülebilirliğinin ekonometrik testi için vektör otoregresif temelli Johansen eş-bütünleşme testi kullanılmıştır. Eşbütünleşme (kointegrasyon) için popüler olan yöntem, birim kök sınaması yapılması ve sonrasında Engle ve Granger'ın iki aşamalı sürecinin uygulanmasıdır4.

Sayfa/Page | 126

Engle-Granger (1987), yaklaşımı oldukça eleştirilmiştir. $\mathrm{Bu}$ eleştirilerin giderilmesi için farklı metotlar geliştirilmiştir ${ }^{5}$. Bu metotların en yaygın kullanılanı Johansen eş-bütünleşme yaklaşımıdır. Johansen eşbütünleşme yaklaşımı için şu VAR(p)modeli

$$
y_{t}=A_{1} y_{t-1}+\cdots+A_{p} y_{t-p}+B x_{t}+\varepsilon_{t}
$$

Formülde;

$y_{t}$ I(1) değişkeninin bir k vektörünü ifade etmektedir ve durağan değildir. $x_{t}$; deterministik değişkenlerin $\mathrm{d}$ vektörünü, $\varepsilon_{\mathrm{t}}$ ise yenilik vektörünü temsil etmektedir. Denklem 1 deki vektör otoregresif sürecinin birinci farkı alındığında;

$$
\begin{aligned}
& \Delta y_{t}=\pi \mathrm{y}_{\mathrm{t}-1}+\sum_{\mathrm{i}-1}^{\mathrm{p}-1} \tau_{\mathrm{i}} \Delta \mathrm{y}_{\mathrm{t}-1}+\mathrm{Bx}_{\mathrm{t}}+\varepsilon_{\mathrm{t}} \\
& \pi=\sum_{\mathrm{i}=1}^{\mathrm{p}} \mathrm{A}_{\mathrm{i}}-\mathrm{I} \text { ve } \tau_{i}=-\sum_{j=i+1}^{p} A_{j}
\end{aligned}
$$

$\pi$ : matrisinin indirgenen düzeyi olarak düşünülen eş-bütünleşme hipotezi

$\alpha$ ve $\beta$ ( kxr )boyutlu ve seviyesi $r$ olan iki matrisi simgelemektedir. Johansen yöntemi test istatistikleri iz ( $\lambda$ trace) ve maksimum öz ( $\lambda$ mak) değerleri yardımıyla belirlenmektedir.

${ }^{4}$ T.C. David, R.Moghadam, Capital and Trade as Engines of Growth in France: An Application of Johansen's Cointegration Methodology, IMF Staff Papers, Vol. 40 (3), 1993, p. 545.

${ }^{5}$ Enders, W., Applied Econometric Time Series, New York: Wiley, 1995, p. 385. 
7.1. Birim Kök Testi İle Durağanlık Tespiti

Tablo 6: ADF Birim Kök Testi Sonuçları

\begin{tabular}{|c|l|l|l|l|}
\hline \multirow{2}{*}{ Değişkenler } & \multicolumn{3}{|c|}{ ADF Birim Kök Testi Sonuçları } & \multirow{2}{*}{ Kritik } \\
\cline { 2 - 5 } & $\begin{array}{l}\text { 1994:04- } \\
\mathbf{2 0 1 2 : 0 3}\end{array}$ & $\begin{array}{l}\text { 1994:04- } \\
\mathbf{2 0 1 2 : 0 3}\end{array}$ & $\begin{array}{l}\text { 1994:04- } \\
\mathbf{2 0 1 2 : 0 3}\end{array}$ & Değer(\%1) \\
\hline $\mathrm{R}$ & $-5.531(10)$ & $-1.781(11)$ & $-0.631(11)$ & -3.732 \\
\hline $\mathrm{E}$ & $-0.282(9)$ & $-1.881(9)$ & $-0.265(11)$ & -3.533 \\
\hline$\Delta \mathrm{R}$ & $-3.511(9)$ & $-4.876(10)$ & $-3.702(9)$ & -3.641 \\
\hline$\Delta \mathrm{E}$ & $-4.911(8)$ & $-3.919(8)$ & $-4.955(11)$ & -3.135 \\
\hline
\end{tabular}

Sayfa/Page | 127

İGÜSBD

Cilt: 1 Sayı: 2

Ekim /

October 2014

Test biçimi olarak düzey değerde bütün değişkenler için sabit terim

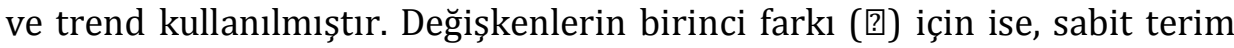
kullanılmıștır. Parantez içi değerler değişkenlerin, AIC'ye göre belirlenmiş uygun gecikme uzunluğunu belirtmektedir.

Tablo 6'da, birim test sonuçlarına göre $R_{t}$ ve $E_{t}$ değişkenlerinin aynı dereceden bütünleștikleri ve ikisinin de I(1) oldukları görülmüştür. Dolayısıyla, eş-bütünleşme için gerekli ön koşul sağlanmıștır. Johansen yönteminin uygulanabilmesi için uygun gecikme sayısının belirlenmesi gerekmektedir. Çalışmada gecikme uzunluğu belirlenirken kullanılan kriterler ve elde edilen gecikme uzunlukları Tablo 7 de sunulmuştur.

Tablo 7: Gecikme Uzunluğu Tespiti

\begin{tabular}{|l|l|l|l|}
\hline Dönem & $\begin{array}{l}\text { Gecikme } \\
\text { Uzunluğu }\end{array}$ & Kullanılan Kriter & $\begin{array}{l}\text { Otokorelasyon } \\
\text { Testi }\end{array}$ \\
\hline 1994:04-2003:02 & 3 & & 0.382 \\
\hline 2003:03-2012:01 & 3 & \multirow{4}{*}{ AIC CS, HQ } & 0.623 \\
\hline 1994:04-2013:04 & 3 & & 0.394 \\
\hline
\end{tabular}

${ }^{6}$ Akaike bilgi kriteri (Akaike Information Criterion: AIC).Schwarz bilgi kriteri (Schwarz information criterion: SC). Hannan Quin bilgi kriteri (HannanQuin information criterion: $\mathrm{HQ}$ ) 
Tablo 7 ye göre gecikme uzunluğunun 3 olduğu modellerde otokorelasyon sorununun olmadığı görülmüștür.

\subsection{Eş-bütünleşme Testi}

Tablo 8'e göre, bütün değişkenler I(1) olduğu için gelirler ve giderler

Sayfa/Page | 128

İGÜSBD Cilt: 1 Sayı: 2 serisi arasındaki eş-bütünleşme ilişkisi Johansen yöntemi yardımıyla araştırılabilir durumdadır. Es-bütünleşmenin varlığı ve es-bütünleşme vektörü sayısını belirlemek amacıyla elde edilen iz değeri test sonuçları Tablo 7'de sunulmuştur.

Tablo 8: Eş-bütünleşme Test Sonuçları

\begin{tabular}{|c|c|c|c|c|c|}
\hline & \begin{tabular}{|l} 
Boş \\
Hipotez
\end{tabular} & $\begin{array}{l}\text { Alternatif } \\
\text { Hipotez }\end{array}$ & & $\begin{array}{l}\text { \%5 Kritik } \\
\text { Değer }\end{array}$ & Karar \\
\hline \multirow{3}{*}{$\begin{array}{l}\text { 1994:04- } \\
\text { 2003:02 }\end{array}$} & $\begin{array}{l}\lambda \text { trace } \\
\text { testi }\end{array}$ & & $\begin{array}{l}\lambda \text { trace } \\
\text { testi }\end{array}$ & & \\
\hline & $\mathrm{r}=0$ & $r>0$ & 17.231 & 16.231 & $\begin{array}{l}\text { eş-bütünleşme } \\
\text { mevcut }\end{array}$ \\
\hline & $\mathrm{r}<1$ & $r>1$ & 3.761 & 3.912 & \\
\hline \multirow{3}{*}{$\begin{array}{l}\text { 2003:03- } \\
\text { 2012:01 }\end{array}$} & $\begin{array}{l}\lambda \text { trace } \\
\text { testi }\end{array}$ & & $\begin{array}{l}\lambda \text { trace } \\
\text { testi }\end{array}$ & & \\
\hline & $r=0$ & $r>0$ & 38.331 & 13.243 & $\begin{array}{l}\text { eş-bütünleşme } \\
\text { mevcut }\end{array}$ \\
\hline & $\mathrm{r}<1$ & $r>1$ & 1.921 & 4.231 & \\
\hline \multirow{3}{*}{$\begin{array}{l}\text { 1994:04- } \\
\text { 2013:04 }\end{array}$} & $\begin{array}{l}\lambda \text { trace } \\
\text { testi }\end{array}$ & & $\begin{array}{l}\lambda \text { trace } \\
\text { testi }\end{array}$ & & \\
\hline & $\mathrm{r}=0$ & $r>0$ & 15.513 & 17.351 & $\begin{array}{l}\text { eş-bütünleşme } \\
\text { mevcut }\end{array}$ \\
\hline & $\mathrm{r}<1$ & $r>1$ & 0.812 & 3.143 & \\
\hline
\end{tabular}


Tablo 7 de izlendiği gibi $\lambda$ trace testi sonuçlarına değişkenler arasında eş-bütünleşme ilişkisinin olmadığı boş hipotezi (r=0) reddetmektedir. Çünkü $\lambda$ trace sonucu, $\% 5$ kritik değerden daha büyüktür. $\mathrm{Bu}$ durumda eş-bütünleşme ilişkisinin varlığı kabul edilmektedir.

\subsection{Uzun Dönem Analizi}

Gelir ve gider değişkenleri arasındaki eş bütünleşmenin varlığl, gelirler ile giderler arasında bir ilişkinin olduğu sonucunu doğurabilir. Fakat bu durum tek başına yeterli değildir. Bu nedenle uzun dönem eşbütünleşme denklemine bakılmalıdır.

Tablo 9: Eş-bütünleşme Denklemleri ve Uzun Dönem Katsayıları

\begin{tabular}{|c|c|c|c|}
\hline & & $\mathbf{R}$ & $\mathbf{E}$ \\
\hline \multirow{3}{*}{$\begin{array}{l}\text { 1994:04- } \\
\text { 2003:02 }\end{array}$} & \multirow[b]{2}{*}{ Eş-bütünleşme Uzun Dönem Katsayısı } & \multirow[b]{2}{*}{1.000} & -0.871 \\
\hline & & & $(0.112)$ \\
\hline & Eş-bütünleşme denklemi & \multicolumn{2}{|c|}{$\mathrm{R}=1.062+0.871$} \\
\hline \multirow{3}{*}{$\begin{array}{l}\text { 2003:03- } \\
2012: 01\end{array}$} & \multirow{2}{*}{ Eş-bütünleşme uzun Dönem Katsayısı } & \multirow{2}{*}{1.000} & -0.8021 \\
\hline & & & $(0.033)$ \\
\hline & Eş-bütünleşme denklemi & \multicolumn{2}{|c|}{$\mathrm{R}=1.571+0.8021$} \\
\hline \multirow{3}{*}{$\begin{array}{l}\text { 1994:04- } \\
2013: 04\end{array}$} & \multirow{2}{*}{ Eş-bütünleşme Uzun Dönem Katsayısı } & \multirow[b]{2}{*}{1.000} & -0.7109 \\
\hline & & & $(0.0211)$ \\
\hline & Eş-bütünleşme denklemi & \multicolumn{2}{|c|}{$\mathrm{R}=1.021+0.8828$} \\
\hline
\end{tabular}

Tablo 8 de eş-bütünleşme denklemlerine baktığımızda gelirler değişkeni ile giderler değişkeni birbirleriyle pozitif ilişki halindedir. Çalışmamızın eş-bütünleşme denklemlerinde katsayılar $0.87,0.80$ ve 0.88 çıkmıştır. Bu durum teorik açıklamaları desteklemektedir. Denklemdeki sonuçların anlamı, 100 birimlik dış harcamanın ilk dönemde 87 biriminin, ikinci dönemde 80 biriminin ve üçüncü dönemde 88 biriminin gelirler ile karşılandığıdır. Eş-bütünleşme denklemlerindeki uzun dönem

Sayfa/Page | 129

İGÜSBD

Cilt: 1 Sayı: 2

Ekim /

October 2014 
katsayılarının 1 den küçük oluşu, Türkiye'nin cari açık sorununu zayıf güçte sürdürülebilir olduğunu ifade etmektedir.

\section{Sonuç}

Çalışmada cari açığın ülke ekonomileri için ne derece önemli olduğu

Sayfa/Page | 130

Türkiye ekonomisi örneği ile ele alınmıştır. Özellikle finansal krizlerin erken uyarı sinyalleri kapsamında önemli yer tutan cari açık sorunu, ülkemiz ekonomik gerçekleşmeleri çerçevesinde analiz edilmiştir.

Çalışmada Türkiye için 1994:04-2012:03 dönemleri için cari açığın sürdürülebilir olup olmadığı VAR analiz kullanılarak Johansen eşbütünleşme yöntemiyle test edilmiştir. Çalışmamızda vardığımız sonuçlardan ilki seriler arasında tüm dönemlerde eş-bütünleşme ilişkisinin olduğudur. Diğer bir ulaşılan sonuç ise her ne kadar kısa dönemde sapmalar olsa da uzun dönemde söz konusu sapmaların ortadan kalktı̆̆ıdır. Ekonometrik modelimize göre Türkiye'nin cari açık problemi zayıf bir şekilde sürdürülebilmektedir.

$\mathrm{Bu}$ çalışma bizlere gösterdi ki Türkiye için cari açık sorunu yadsınamaz. Bu gerçekten yola çıkarak cari açı̆̆ın azaltılması için turizm gelirlerini teşvik edici politikaların geliştirilmesi, ihracatın arttırılması ve ithalatın bastırılması cari açığın sürdürülebilirliğindeki zayıf formu, güçlü forma dönüștürebilecektir. Aksi takdirde Türkiye'nin ciddi bir finansal krizle karşı karşıya kalabilecek ve onarılması güç sorunlara neden olabilecektir.

\section{KAYNAKÇA}

DAVID, T.C., R. MOGHADAM, Capital and Trade as Engines of Growth in France: An Application of Johansen's Cointegration Methodology, IMF Staff Papers, Vol. 40 (3), 1993, pp. 542-566.

ENDERS, W., Applied Econometric Time Series, New York: Wiley, 1995.

ENGLE, Robert F., Clive W. J. GRANGER, “Co-Integration and Error Correction: Represention, Estimation and Testing”, Econometrica, 55 (2), 1987.

FOUNTAS, S., WU, J. L., "Are The U.S. Current Account Deficits Really Sustainable?", International Economic Journal, (13) 3, 1999. 
GÖÇER, İ., M. MERCAN “Türkiye Ekonomisinde Cari Açı̆̆ın Sürdürülebilirliği: Sınır Testi Yaklaşımı", Finans Politik \& Ekonomik Yorumlar, 48 (562), 2011.

IMF, Wold Economic Outlook, April 2011.

MARINHEIRO, C.F., "Ricardian Equivalence, Twin Deficits, and the Feldstein- Horioka Puzzle in Egypt", Grupo de Estudos Monetarios e Financeiros, Faculty of Economics University of Coimbra, Portugal, 2006, http://evds.tcmb.gov.tr (Erişim: 27.08.2013).

MATSUBAYASHI, Y. "Are US Current Account Deficits Unsustainable? Testing 131ort he Private and Government Intertemporal Budget Constraints", Japan and the World Economy, Vol:17, 2005.

PEKER, O. “Türkiye'deki Cari Açlk Sürdürülebilir mi? Ekonometrik Bir Analiz", Kocaeli Üniversitesi Sosyal Bilimler Enstitüsü Dergisi, 17(1), 2009.

TELATAR, O. Murat, Harun TERZI, “Türkiye'de Ekonomik Büyüme ve Cari İşlemler Dengesi İlişkisi”, Atatürk Üniversitesi İktisadi ve İdari Bilimler Dergisi, 23:2,2009, ss. 119-134.

YÜCEL, Fatih, Rüstem YANAR. “Türkiye'de Cari İşlem Açılkları Sürdürülebilir mi? Zaman Serileri Perspektifinden Bir Bakış”, Ç.Ü. Sosyal Bilimler Enstitüsü Dergisi, Cilt 14, Sayı 2, 2005. 
Sayfa/Page | 132 İGÜSBD Cilt: 1 Sayı: 2 Ekim / October 2014

\section{Summary}

The aim of this study is to test if current deficit of Turkey is sustainable or not. Turkey was tested by Johansen's co integration method by using the data of 1994:04- 2012:03. According to the result of empirical analysis, cointegration relation exists and it was understood that the current account deficit has been determined as weakly sustainable.

Current account deficit has been used much more in the literature after the liberalization in the 80's. Use to be lnown that Turkey has been struggling with current account deficit. Because of this fact, Turkey's current account deficit was examined in this study by using cointegration. Before cointegration, all variables were made stationary. After that, Johansen co integration test was used covering 1994-2012. The reason of choosing that period is that Turkey faced two important crisis in 1994 and 2001. In addition, Turkey was affected from 2008 Global crisis as well. So selected period contains mentioned terms. By this study, we can understand the effect of financial crisis on Turkey economy and how can struggle with.

As a result of study, we understood that co-integration relation exists and it was understood that the current account deficit has been determined as weakly sustainable. So political and economic authorities take into consideration to this fact and create new policies to strugle with current account deficit. .Tourism income and import income are the only real way to overcome this problem. Increasing of import rate and tourism income helps Turkey in order to overcome current account deficit. 